\title{
Creative Concept Design of Classified Dustbin Optimal Configuration
}

\author{
Liu lizhen \\ Wenzhou Vocational \& Technical College, Wenzhou. 325035 \\ Email: 1918427983@qq.com
}

Keywords: Dustbin, Optimization, Creation, Design

Abstract: After field visits, it is found that an easy use of an object may make users feel very positive, which also is a good experience. Therefore, a reasonable size of project is closely related to the feeling of user upon using. Ergonomic data is a size design data which is more suitable for many people. It works in such way that according to the use procedures of people, it will find corresponding data. Such data will be used as reference for designing a more reasonable classified dustbin which is more suitable for users.

\section{Introduction}

As the society develops, people has an increasing living level, accordingly the waste generated are increased day by day. For this reason, the classification and recycling of waste becomes an serious issue. To build a better environment, everyone should try our best to protect our surroundings. The top priority to protect environment is to dispose the waste generated in our daily life, so the dustbin is first point to be considered for disposal of waste. From this, the dustbin plays a very important role is environmental protection and a good design of dustbin provides us convenience in our life and decorates our home. Classified Dustbins are essential part in our life, which can be seen at subway stations, bus stations, parks, attractions, communities and sides of the public road. So, there are really connected with us and serve as the representation of city civilization. However, the current classified dustbins in market not come to play and there are some problems not solved. While we appeal to classify waste, the design of classified dustbin also keeps pace with the times. To improve environment effectively, we should change the public facilities around us.

\section{The Overseas and Domestic Research Status}

\subsection{Domestic Dustbin Status}

In the investigation of the classified dustbin at public area in our country, there are still some existing problems. For example,

The opening position and size are not in line with ergonomic theory and it will be inconvenient for user to use. Upon clearing waste, the rectangular dustbin is hard to clear due to blind sides, leading to waste paste on the dustbin for a long time to cause troubles for cleaner. Design of Many dustbins in shape and color shows unclear meaning so that users cannot get correct suggestion. The 
marks on classified dustbin are unclear, only such words as recoverable, non-recyclable and hazardous waste shown. The knowledge on waste classification is not fully mastered by people, so this dustbin is useless in waste classification. The classified dustbins in our country are open, on a hot day, the peel and leftover food in it will generate plenty of foul smell under evaporation, as shown in Fig.1.

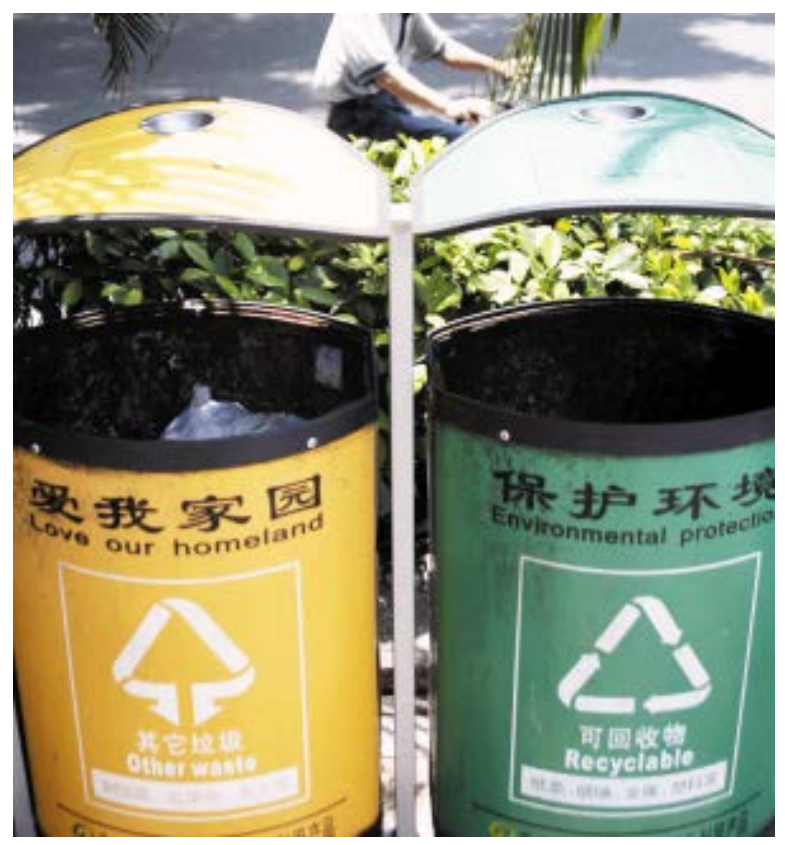

Fig.1 Common dustbin status

\subsection{Research status of oversea classified dustbin}

Germany: gray dustbin is for waste that cannot be recycled, yellow dustbin for packaging waste with green signs, Brown organic dustbin for organic refuse. The storage containers include glass containers, paper or cardboard containers, clothing and shoes containers.

Japan: the classified dustbins line the street which several dustbins arranged at a same place for classification. Besides, on the dustbin, both words and specific patterns for classification are shown clearly.

Sweden: Two dustbins provided, brown one is for food waste and green one for other waste which cannot be clearly classified. For the rest of waste, including plastic carton packaging, newspapers and magazines, metal, wood (beverage bottles and beer cans excluded), such wastes will be sent to waste collection station in communities or waste collection center in town by users and can be abandoned. The beverage bottles and beer cans will be sent back to recycle bin of supermarkets, and one bottle is about a krone. The better classification of waste, the lower cost to be spent disposing waste will be.

Korea: the dustbins arranged at public area are mainly used to collect glass bottles, cans, plastic bottles, general rubbish and junk food, and each dustbins have corresponding color, icons and words.

Finland: the dustbins have four colors for different purposes: brown dustbin for collecting renewable biological waste, green one for old newspaper, appliances and other electronic products, black dustbins for all non-renewable waste.

Italy: daily wastes are classified to kitchen organic matter, paper, plastic products, metal, glass, non-recyclable products. Additionally, edible oil, dangerous goods also need to be recycled 
separately.

The oversea status is shown as Fig.2 and Fig.3.

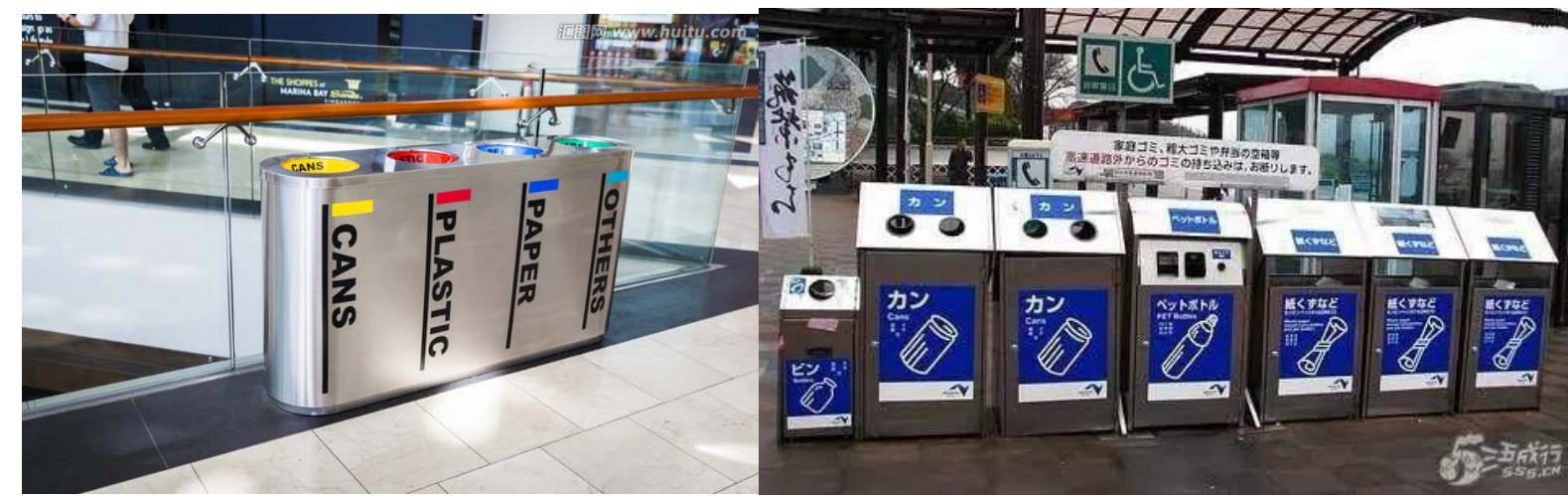

Fig.2 Oversea classified dustbin reference diagram Fig.3 Oversea classified dustbin reference diagram

\section{The Dustbin Size}

Height of dustbin: A reasonable dustbin is designed to a product which the waste can be dropped in easily and can be taken out and cleaned easily. The height of dustbin is lower than the half height when people stand up and rise hands up. Based on this, the height of dustbin should be 800-1000mm, As shown in Fig.4.

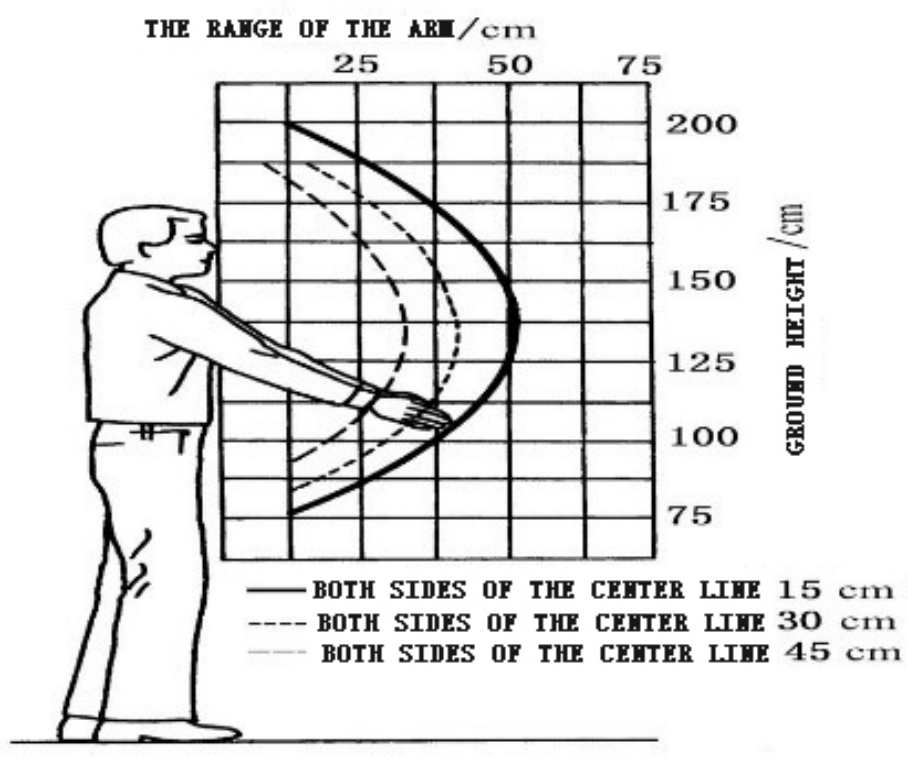

Fig.4 Standing position hands function height reference diagram

\section{Program design drawing}

Dustbin opening: the opening should meet use requirements of most people so the height of upper edge should not lower than $95 \%$ people hand height and the lower should lower than 5\% people elbow height. Only in such way, it can realize that tall man doesn't need to squat and short man doesn't have to lift on to use dustbin, as shown in Fig.5. 

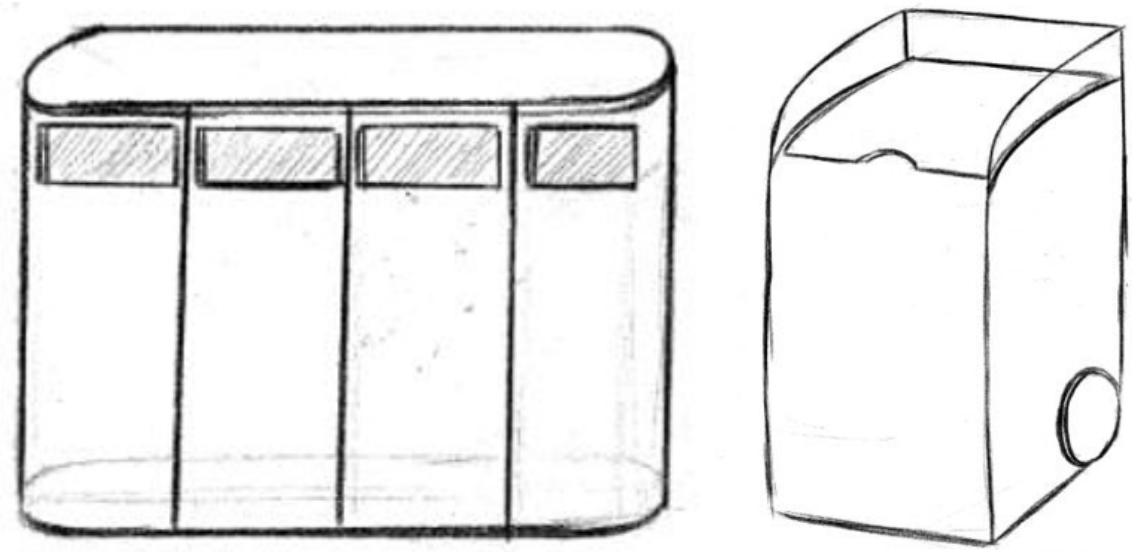

Fig.5 Design Draft Fig.6 Design Draft

Only the dustbin is easy to use and it can change throwing rubbish casually, as shown in Fig.6.

The opening height of dustbin should be designed with higher enough so that pedestrians can throw waste in successfully. It should not be oversize, because the waste in dustbin may cause irksome and rainwater is easy to splash into the dustbin, leading to increased germ due to waste rotting, as shown in Fig.7.

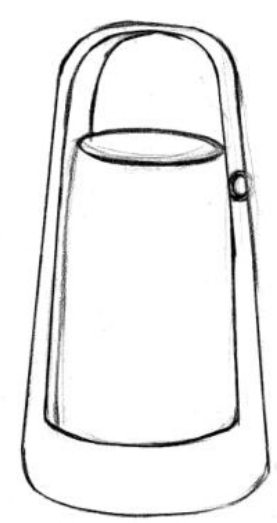

Fig.7 Draft

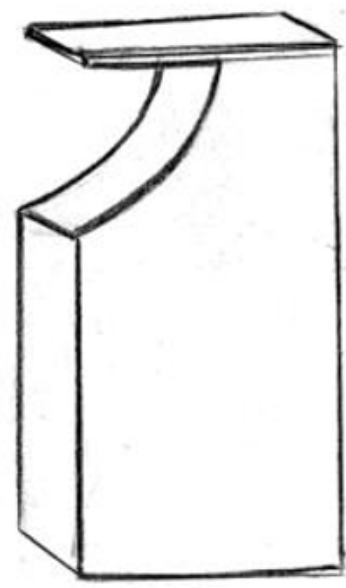

Fig.8 Design Draft

The size of opening should be greater than that of general waste. The opening should face the side where more pedestrians pass by, so that they can put waste into dustbin easily without spending time to find opening, as shown in Fig.8.

The waste in dustbin arranged on the street includes some light waste such as bottles, cans, papers, accordingly, the size of opening should greater than the diameter of bottles and the angle of inclination should also be taken into consider for easy putting in. The diameter of bottles is less than $100 \mathrm{~mm}$ generally, including the angle of inclination included, so the height of opening is suggested to greater than $120 \mathrm{~mm}$, as shown in Fig.9-12. 

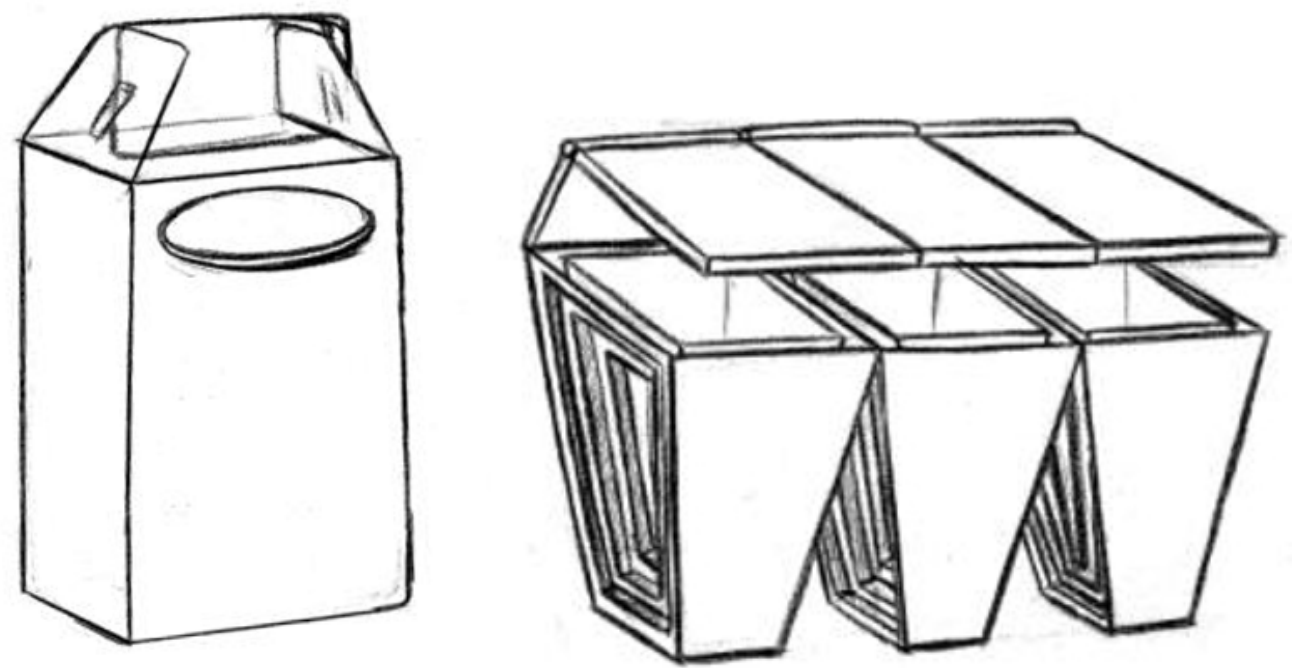

Fig.9 Design Draft Fig.10 Design Draft

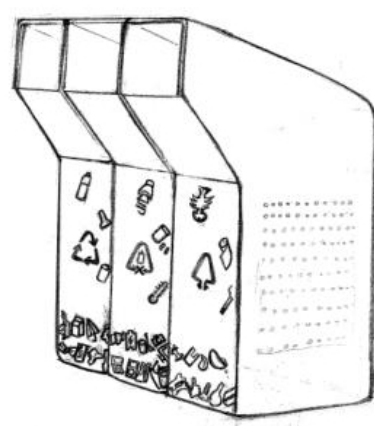

Fig.11 Design Draft

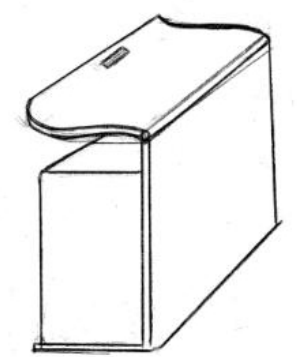

Fig.12 Design Draft

\section{Determination of Plan Draft, Manual effect drawing and dimension drawing}

Fig.5.1 Design Draft

After the study of classified dustbin structure and its details, the classification mark is designed as "dropping” form to imitate the process of waste falling into the dustbin. The marks of items under each big mark are designed on the dustbin to solve the problem that people are confused to throw waste into suitable dustbin, as shown in Fig.13. 


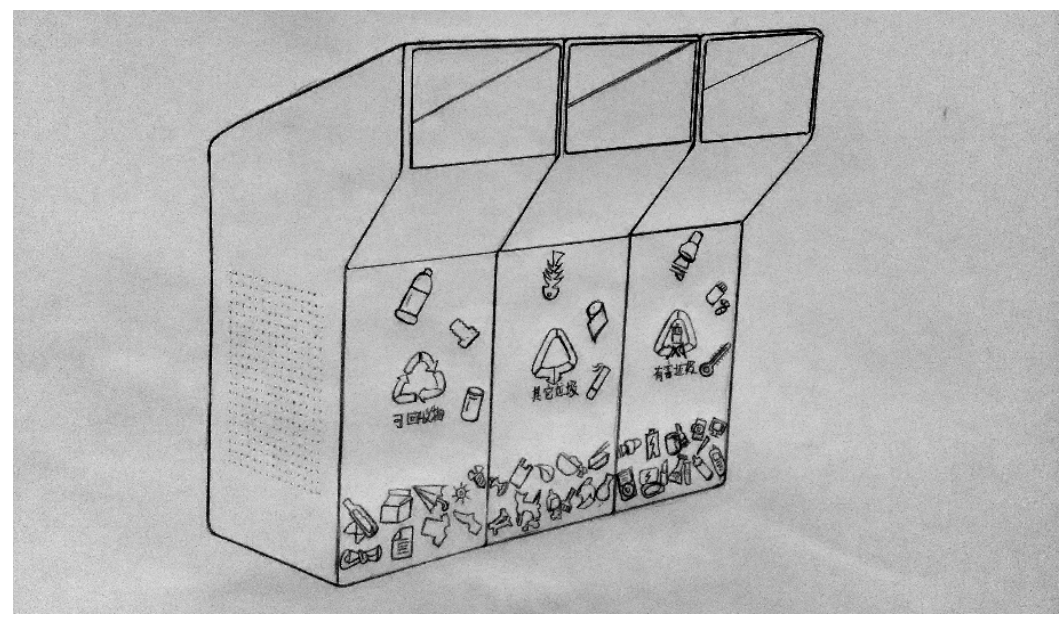

Fig.13 Final plan design draft

The rear cover of dustbin combines with inner bucket of dustbin, making it more convenient to use. The oblique opening of dustbin is helpful to collect waste, as shown in Fig.14.

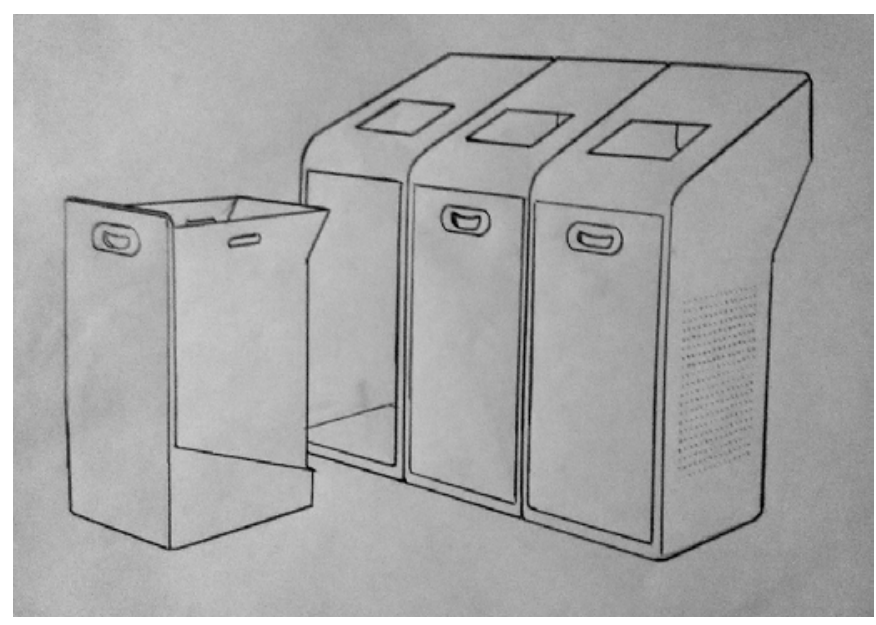

Fig.14 Final plan design draft (II)

\subsection{Manual effect drawing}

It is as shown in Fig.15.

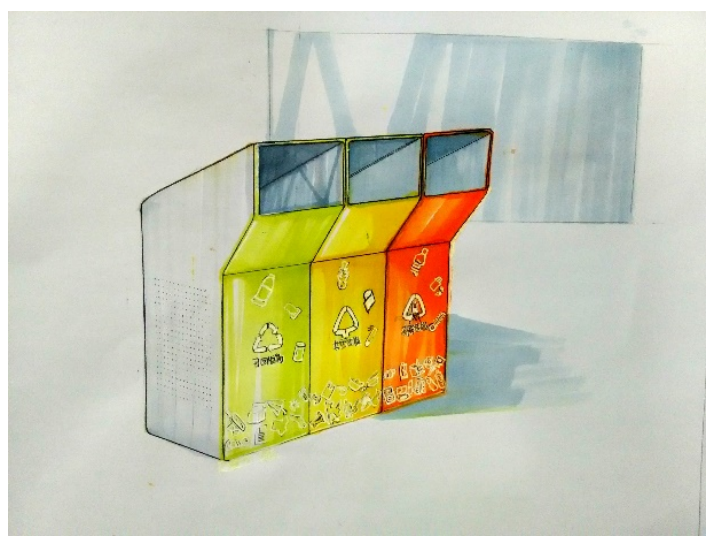

Fig.15 Final plan manual effect drawing 


\subsection{Six views of product and size design drawing}

According to draft, some plan software such as CorelDRAW, Photoshop are used to draw 6 views to illustrate the structure from different aspects. Various tools, such as shadow, morph etc., are skillfully used to show the material of product, as shown in Fig.16.
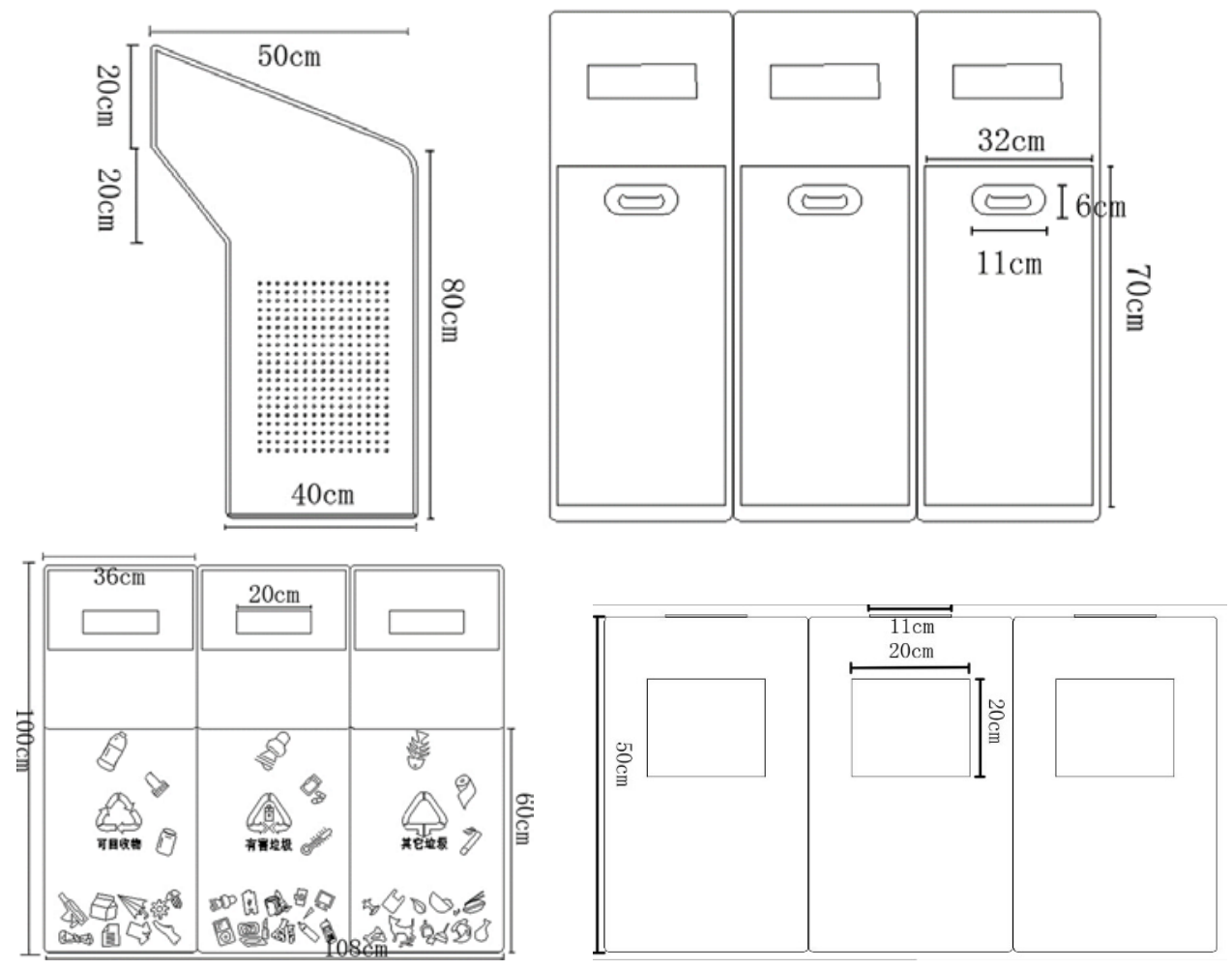

Fig.16 Design size drawing

\section{Product appearance material and material analysis}

A beautiful appearance is important for some outside places such as scenic spots, parks, schools and shopping malls, so the dustbin should be design generous and classy. To achieve that, the material should use stainless steel paint material, because the stainless steel is a new steel type, embracing the strong points of iron, such as high hardness, easy to forge and form. To process into stainless steel, some weakness of iron should be removed such as easy to rust and corrosion so that the service life of stainless steel can be manifold prolonged. The dustbin made of stainless steel can separate with contaminant, and be easy to clean and shorten the microorganism breeding time. It may encourage most people to take out the trash frequently. Besides, stainless steel has many other performances like fire protection function. Compared with ordinary plastic dustbins, it provides good fire-protection function and it is more sturdy and durable. Especially, it can be used for a long time.

The inner bucket is made of galvanized sheet which refers to the steel with zinc coating. Galvanization is a common used corrosion control method which is economic and efficient. Around half of zinc output in the world is used for this process. Galvanized steel plate is coated with a layer of metal zinc on its surface, to prevent corrosion of the surface of the steel plate and to extend its service life. This steel plate is known as galvanized steel plate. 


\subsection{Analysis on product function, structure and appearance modeling}

Functionally, this classified dustbin is helpful to realize correctly throw in classified waste according to the classification marks, and gradient of opening is enabling to collect waste easily and the shape of inner bucket can be used as dustpan to sweep the residual waste into dustbin. The upper of dustbin, there is transparent acrylic boards which can make cleaner see the dustbin clearly without close contact. The exhaust vent at side of dustbin can let out bad smell quickly.

\section{2 on the structure, it contains analysis on external barrel, inner bucket, exhaust vents .}

For the modeling, this classified dustbin is design with whistle as its early form, which provides an alarming function that people should classify the waste to protect our living surroundings. Additionally, there is a highlight design that on the surface of each classified dustbin there are corresponding wastes to be collected, which can help users to dump waste correctly.

\section{3D Model drawing and rendering drawing}

\subsection{D model design drawing}

Based on six views and size drawing, the Rhinoceros is used to create a 3D model to show a strong third dimension to make users feel the features directly, as shown in Fig 17-20.

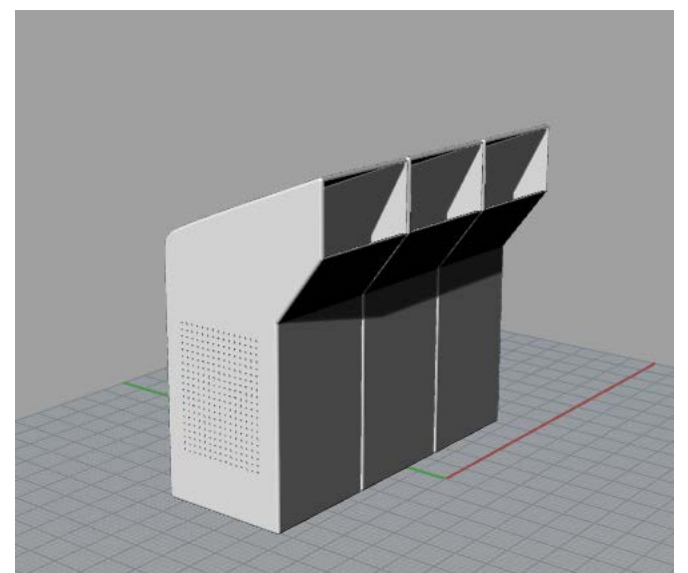

Fig.17 3D model design drawing

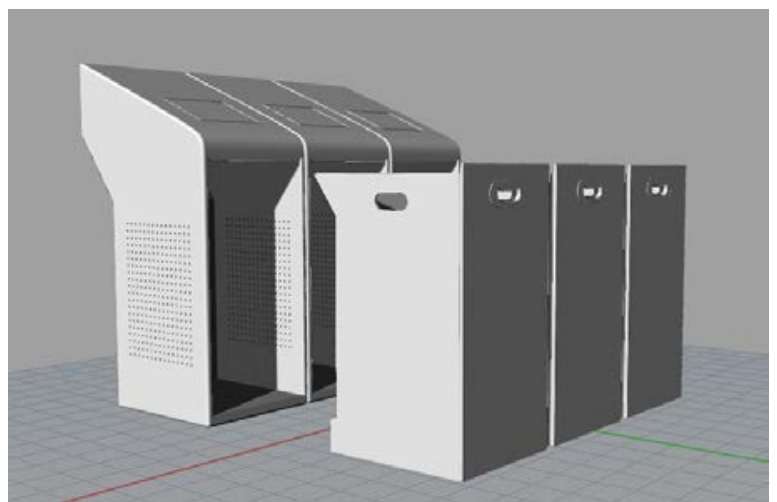

Fig.19 3D model design drawing

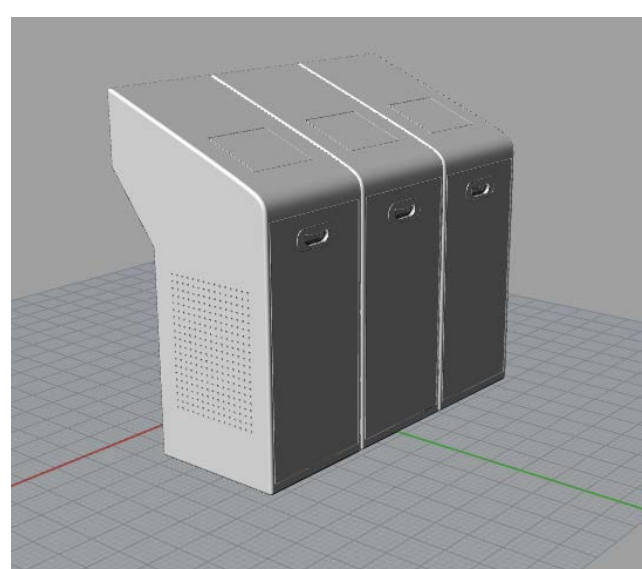

Fig.18 3D model design drawing

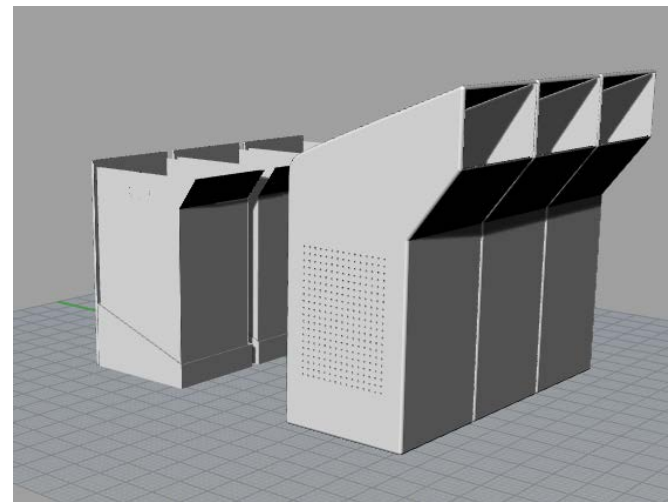

Fig.20 3D model design drawing 
7.2 Rendering effect drawing, as shown in Fig.21-24.

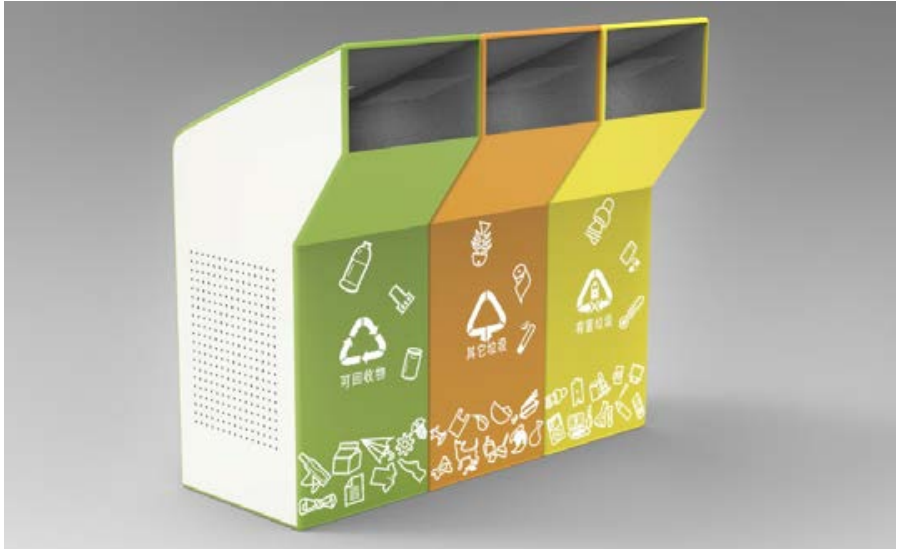

Fig.21 Rendering effect drawing
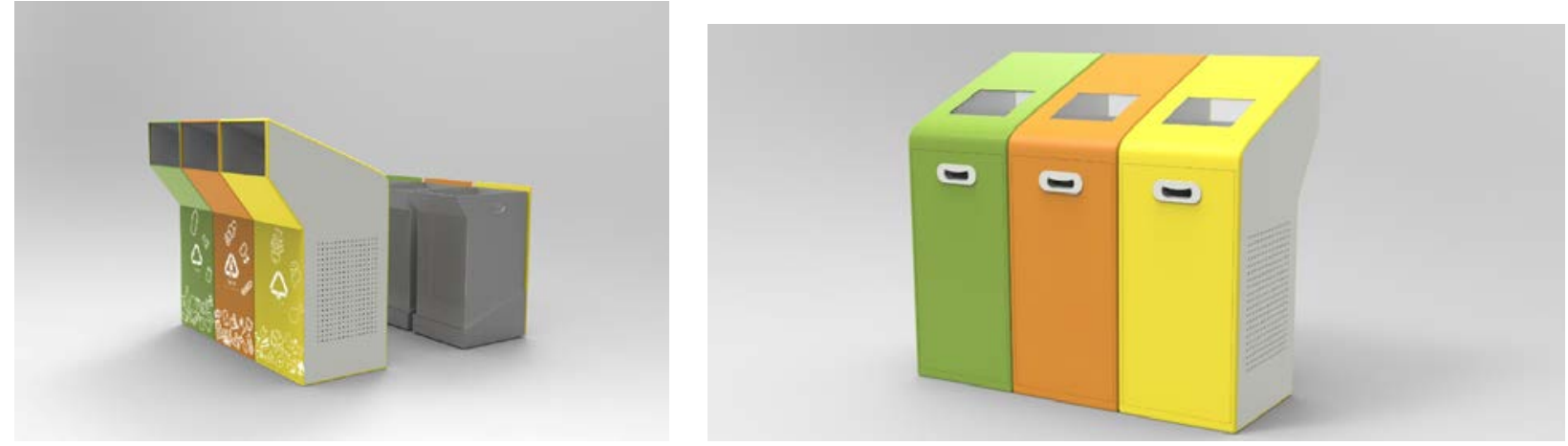

Fig.22 Rendering effect drawing Fig.23 Rendering effect drawing

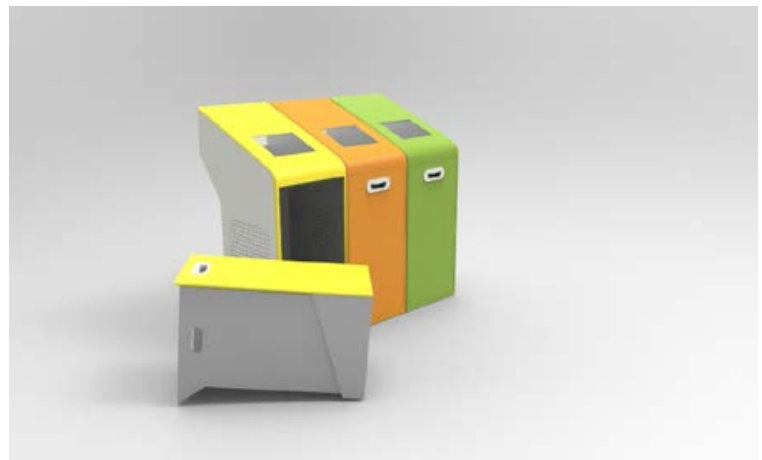

Fig.24 Rendering effect drawing

7.3 Rendering plan design

For color, the Keyshop software is used to render three color plans, as shown in Fig.25. 


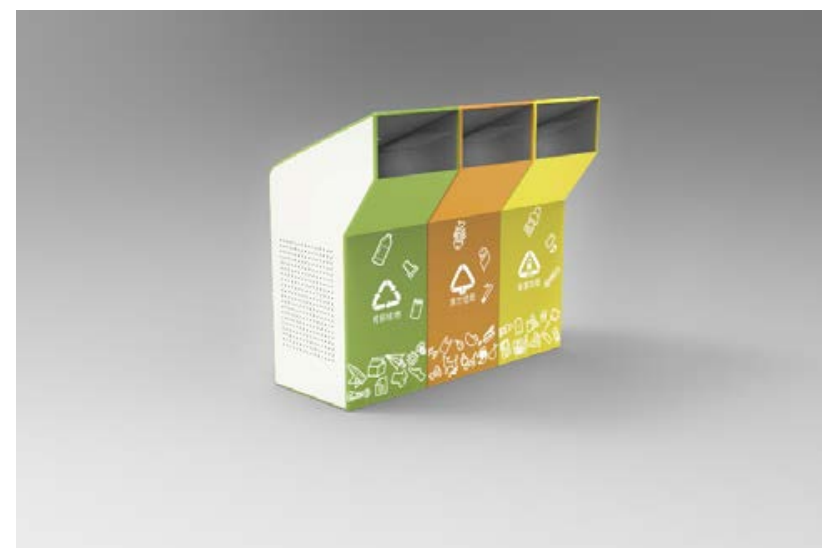

Fig. 25 Rendering plan design

\section{Conclusion}

During the design of classified dustbin, a main considering factor is humanization which is aimed at making users feel convenient and comfortable. With the increasing living standard, users have higher demands. The classified dustbins arranged in public areas are required to meet the basic demands and have its own features and beautiful appearance, so that users may have physical and mental pleasure upon using it.

At very start, the classified dustbin is design to make users more comfortable, change the living surroundings, improve our living quality, make people note the humanistic care of the product, thus having a positive effect.

\section{References}

[1]Jaber Almedeij,Abdalrahman Alsulaili,Jasem Alhomoud. Assessment of grate sag inlets in a residential area based on return period and clogging factor[J]. Journal of Environmental

Management,2005,79(1).

[2]Raymundo Caballero,Purificación Pajuelo,José Ordovás,Eusebio Carmona,Antonio Delgado. Evaluation and correction of nutrient availability to Gerbera jamesonii $H$. Bolus in various compost-based growing media[J]. Scientia Horticulturae,2009,122(2).

[3]Michelle E. Portman,Ruth E. Brennan. Marine litter from beach-based sources: Case study of an Eastern Mediterranean coastal town[J]. Waste Management,2017,69.

[4]Roman Gabl,Daniel Innerhofer,Stefan Achleitner,Maurizio Righetti,Markus Aufleger. Evaluation criteria for velocity distributions in front of bulb hydro turbines[J]. Renewable

Energy,2018,121.

[5]A. L. Rakhmanova,I. O. Rybak. Calculation of the static strength of bars of trash racks[J]. Hydrotechnical Construction,1984,17(7).

[6]Roberts, Mary Rose. In the nick of time[J]. Urgent Communications,2009,27(9).

[7]Lasker, David. Isn't it romantic?[J]. Canadian Interiors,2013,50(3).

[8]Anonymous. Texas Instruments; Routeware Launches RFID Verification Solution for the Waste Industry[J]. Computer Weekly News,2008.

[9]Anonymous. Texas Instruments; Routeware Launches RFID Verification Solution for the Waste Industry[J]. Computer Business Week,2008.

[10]Anonymous. Texas Instruments; Routeware Launches RFID Verification Solution for the Waste Industry[J]. Computer Technology Journal,2008.

[11]Anonymous. Texas Instruments; Routeware Launches RFID Verification Solution for the Waste Industry[J]. Computers, Networks \& Communications,2008.

[12]Lyall, Sutherland. browser [J]. The Architectural Review,2009,225(1343).

[13]Kimberly McCoy,Justin J. Oliver,D. Scott Borden,Scott I. Cohn. Nudging waste diversion at Western State Colorado University: application of behavioral insights[J]. International Journal of Sustainability in Higher Education,2018,19(3). 